\title{
Delirium among Home-Dwelling Elderly after a Recent Hospitalization: An Urgent Need for Effective Nursing Interventions
}

\author{
Henk Verloo $^{\mathrm{a}}$ Céline Goulet ${ }^{\mathrm{a}}$ Diane Morin ${ }^{\mathrm{a}, \mathrm{c}}$ Armin von Gunten ${ }^{\mathrm{b}}$ \\ a Institut Universitaire de Formation et de Recherche en Soins, Faculté de Médecine et Biologie,

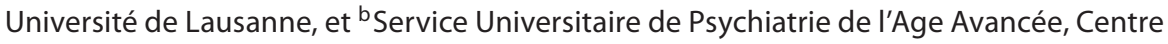 \\ Hospitalier Universitaire Vaudois et Université de Lausanne, Lausanne, Switzerland; ' ${ }^{C}$ Faculté des \\ Sciences Infirmières, Université Laval, Québec, Qué., Canada
}

Due to the pressure applied on the health care system, the majority of hospitalized elderly people are quickly discharged home and the care needed is provided by home care services [1]. An acute confusional state (delirium), which is linked to high percentages of morbidity and mortality, is likely to develop amongst this fragile population [2]. This syndrome, at the crossroads of numerous pathologies, is almost exclusively studied in the hospital environment, which is extremely conducive to the triggering of a delirium episode [3]. The prevalence of delirium among hospitalized elderly people can be as high as $60 \%$. Also, in approximately half of the elderly patients leaving hospital, an episode of delirium (often rather silent) is not detected. By giving careful consideration to the high prevalence of post-hospitalization confusion, the non-detection and the undertreatment of silent delirium episodes, the negative impact of delirium on the elderly person, his/her loved ones as well as on the home care nurses is expected to be reduced [3].

For the elderly person, the consequences of delirium are numerous. At the biological level, delirium increases the risk of early death. After an episode, the elderly individual often has to accept help with activities of daily living due to the physical and cognitive decline, but sometimes with great difficulty. This decline entails, in the longer term, a risk of institutionalization within the year following the delirium episode [4]. Other discomforts and health problems such as falls, dehydration and malnutrition are also associated with an episode of delirium [5]. Delirium is often related to increased fragility, even in healthy elderly people. For those who are already vulnerable or fragile, delirium may be the trigger for a significant physiological decline causing a decrease in quality of life - sometimes up to the point of 
Hospitalization: An Urgent Need for Effective Nursing Interventions

having to leave one's home [6]. From a psychological point of view, acute delirium is a traumatic experience from which the elderly keeps fragmented and agonizing memories. The affected person feels as if he or she is 'out of his or her mind' and lives with the anxiety of experiencing psychosis again and behaving inappropriately towards his or her family and the nurses [7]. Temporary or definitive loss of autonomy frequently causes psychological distress and a decrease in self-esteem with the risk of developing other comorbidities such as depression, overmedication or alcohol abuse [7]. The consequences of delirium not only affect the elderly but also his or her family and the home care nurses. For loved ones, the elderly's functional impairment is demanding and requires an almost continuous presence, allowing only few moments of respite [8]. Delirium that is associated with a progressive functional decline due to dementia often leads relatives, who can no longer assume responsibility for safe care, to resort to early placement in a nursing home. This decision can bring on a sense of failure and induce a depressive state as well as physical and emotional exhaustion [8]. Following the early death of an elderly after delirium, the often shocked family members are likely to experience a difficult if not pathological period of grief [9].

Nurses may experience the repercussions in their work and their person [10]. Patients afflicted by delirium require more support in their daily living activities, repeated, precise and generalized explanations as well as increased monitoring, which substantially increases the workload. Accompanying the confused person and his or her loved ones creates an impression of 'intensive care' for the nurses and sometimes a feeling of threat for their physical and psychological safety, which affects their confidence [11]. Delirium may create conflicts among professionals, but also between professionals and the relatives of confused patients. Nurses report difficulties in managing the unexpected, the increased complexity and the additional burden of care and mistrust towards the unpredictable behavior and reactions of the affected person [12].

In any care environment, nurses should play a predominant role in delirium detection and supervision by ensuring monitoring of manifestations such as agitation, hydration, urinary and fecal elimination, insomnia, disorientation and immobility, as well as the biological parameters associated with underlying pathologies [3]. The goal is to prevent the occurrence of delirium by including specific detection interventions for any elderly person cared for by a home care service [13]. These multifaceted interventions must include a quick and systematic evaluation of risk factors and close monitoring of early warning signs of delirium. It is important to consider both non-modifiable factors (or hardly modifiable factors), which promote the development of delirium (old age, cognitive impairment, chronic diseases), and modifiable factors such as infections or poly-medications [14]. In order to fulfill this role, nurses must know the clinical and early prodromal signs. However, studies in the hospital environment show that they do not recognize the signs of delirium and, consequently, the non-recognition of delirium causes major problems pertaining to care quality, workload and the development of intervention and prevention strategies [1-3].

Strategies for the prevention or early detection of delirium at home are currently unavailable. The evidence accumulated in hospitals [15] and the findings from few clinical intervention studies on the prevention of physical decline in elderly persons at home [13] could serve as foundations for the development of targeted nursing interventions. These interventions should include an educational component supported by an advanced practice paradigm so that nurses quickly detect deterioration signs in the elderly as well as contribute to the development, application and evaluation of standardized tools for risk factor assessment. There is an urgent need to better understand delirium, to develop new home care approaches and to rigorously evaluate their efficiency in terms of the well-being of the elderly as well as of their effectiveness for the health care system itself. 
Verloo et al.: Delirium among Home-Dwelling Elderly People after a Recent

Hospitalization: An Urgent Need for Effective Nursing Interventions

\section{Acknowledgement}

This research received no specific grant from any funding agency in the public, commercial, or not-for-profit sectors.

\section{Disclosure Statement}

No conflict of interest has been declared by the authors.

\section{References}

1 Arcand M, Hébert R: Précis pratique de gériatrie, ed 3. Québec, Maloine-Edisem, 2008.

-2 Witlox J, Eurelings LSM, de Jonghe JFM, Kalisvaart KJ, Eikelenboom P: Delirium in elderly patients and the risk of post discharge mortality, institutionalization, and dementia: a meta-analysis. JAMA 2010;304:443-451.

-3 Inouye SK: Delirium in older persons. N Engl J Med 2006;354:1157-1165.

-4 Pitkälä KH, Laurila JV, Strandberg TE, Tilvis RS: Prognostic significance of delirium in frail older people. Dement Geriatr Cogn Disord 2005;19:158-163.

5 Johansson IS, Larsson BW, Schmidt I, Hall-Lord ML: Family members' perception of health, falls, pressure sores, nutrition, and quality of care related to degree of confusion in nursing home residents. Nordic Journal of Nursing Research and Clinical Studies 2004;24:25-30.

-6 Andrew MK, Freter SH, Rockwood K: Prevalence and outcome of delirium in community and nonacute care settings in people without dementia: a report from the Canadian Study of Health and Aging. BMC Med 2006;4:15.

-7 Breithart W, Gibson C, Tremblay A: The delirium experience: delirium recall and delirium-related distress in hospitalized patients with cancer, their spouses/caregivers, and their nurses. Psychosomatics 2002;43:183-194.

-8 Duppils GS, Wikblad K: Patients' experiences of being delirious. J Clin Nurs 2007;16:810-818.

-9 Covinsky KE, Palmer RM, Fortinsky RH, Counsell SR, Stewart AL, Kresevic D, Landefeld CS: Loss of independence in activities of daily living in older adults hospitalized with medical illnesses: increased vulnerability with age. J Am Geriatr Soc 2003;51:451-458.

10 Hallberg IR: Impact of delirium on professionals. Dement Geriatr Cogn Disord 1999;10:420-425.

-11 Granberg A, Engberg IB, Lundberg D: Intensive care syndrome: a literature review. Intensive Crit Care Nurs 1996;12:173-182.

12 Stenwall E, Jönhagen ME, Sandberg J, Fagerberg I: The older patient's experience of encountering professional carers and close relatives during an acute confusional state: an interview study. Int $\mathrm{J}$ Nurs Stud 2008;45:1577-1585.

-13 Hébert R, Robichaud L, Roy PM, Bravo G, Voyer L: Efficacy of a nurse-led multidimensional preventive program for older people at risk of functional decline. A randomized controlled trial. Age Ageing 2001;30:147-153.

14 Inouye SK, Charpentier PA: Precipitating factors for delirium in hospitalized elderly persons. Predictive model and interrelationship with baseline vulnerability. JAMA 1996;275:852-857.

15 Inouye SK, Bogardus SJ, Charpenter PA, Summers LL, Acampora D, Holford TR, Cooney LM: A multi-component intervention to prevent delirium in hospitalized older patients. N Engl J Med 1999; 340:669-676. 